\title{
CRISPR/Cas9 Editing of Viral Receptors and Biotechnological Approach to Host Resistance ${ }^{\dagger}$
}

\author{
Jiří Hejnar 1,*, Anna Koslová ${ }^{1}$, Pavel Trefil ${ }^{2}$, Jiři Plachý ${ }^{1}$, Markéta Reinišová ${ }^{1}$, Dana Kučerová ${ }^{1}$, \\ Jitka Mucksová ${ }^{2}$ and Jiří Kalina ${ }^{2}$ \\ 1 Institute of Molecular Genetics, Czech Academy of Sciences, Vídeňská 1083, CZ-14220 Prague 4, \\ Czech Republic; anna.lounkova@gmail.com (A.K.); jiri.plachy@img.cas.cz (J.P.); \\ marketa.reinisova@img.cas.cz (M.R.); dana.kucerova@img.cas.cz(D.K.) \\ 2 BIOPHARM, Research Institute of Biopharmacy and Veterinary Drugs, CZ-25449 Jílové u Prahy, \\ Czech Republic; pavel.trefil@bri.cz (P.T.); jitka.mucksova@bri.cz (J.M.); jiri.kalina@bri.cz (J.K.) \\ * Correspondence: hejnar@img.cas.cz \\ † Presented at Viruses 2020-Novel Concepts in Virology, Barcelona, Spain, 5-7 February 2020. \\ Published: 8 June 2020
}

Keywords: Avian leukosis virus subgroup $\mathrm{J} ; \mathrm{Na}^{+} / \mathrm{H}^{+}$exchanger type 1; CRISPR/Cas9 genome editing in chicken; primordial germ cells; resistance to virus infection

Avian sarcoma and leukosis virus (ASLV), diversified into seven phylogenetically relative subgroups (A, B, C, D, E, J, and K), present as either exogenous or endogenous viruses in domestic chicken. These subgroups are unequivocally classified by subgroup-specific receptor usage. The ALV-J subgroup enters the cell through a receptor identified as the chicken $\mathrm{Na}^{+} / \mathrm{H}^{+}$exchanger type 1 (chNHE1) with twelve predicted transmembrane segments and the prominent extracellular loop 1. In multiple galliform species, the single W38 deletion or substitution makes the NHE1 receptor molecule resistant to virus entry [1,2]. On the other hand, resistant alleles for NHE1 have not been found in chicken.

We recently established a new technique for transgenesis in chicken, which improves the efficiency of gene modification (including gene introduction, CRISPR/Cas9-mediated knockouts and knockins) and skips the chimeric Go stage [3]. This technique has been employed to introduce the W38 deletion into the chNHE1 and biotechnologically prepare ALV-J-resistant chicken line. We present the CRISPR/Cas9-mediated deletion of W38 in chicken primordial germ cells and the successful production of the gene-edited birds. The resistance to ALV-J was examined both in vitro and in vivo and the chickens homozygous in W38 deletion was found to be ALV-J-resistant, in contrast to DW38 heterozygotes and wild-type birds, which were ALV-J-susceptible. Deletion of W38 did not manifest any visible side effects. Our data clearly demonstrate the antiviral resistance conferred by precise CRISPR/Cas-9 gene editing in the chicken [4]. Furthermore, our highly efficient CRISPR/Cas-9 gene editing in primordial germ cells represents a substantial addition to the gene technology available for chicken, an important food source and research model.

\section{References}

1. Kučerová, D.; Plachý, J.; Reinišová, M.; Šenigl, F.; Trejbalová, K.; Geryk, J.; Hejnar, J. Nonconserved tryptophan 38 of the cell surface receptor for subgroup J avian leukosis virus discriminates sensitive from resistant avian species. J. Virol. 2013, 87, 8399-8407.

2. Koslová, A.; Kučerová, D.; Reinišová, M.; Geryk, J.; Trefil, P.; Hejnar, J. Genetic resistance to avian leukosis viruses induced by CRISPR/Cas9 editing of specific receptor genes in chicken cells. Viruses 2018, 10, 605. 
3. Trefil, P.; Aumann, D.; Koslová, A.; Mucksová, J.; Benešová, B.; Kalina, J.; Wurmser, C.; Fries, R.; Elleder, D.; Schusser, B.; et al. Male fertility restored by transplanting primordial germ cells into testes: A new way towards efficient transgenesis in chicken. Sci. Rep. 2017, 7, 14246.

4. Koslová, A.; Trefil, P.; Mucksová, J.; Reinišová, M.; Plachý, J.; Kalina, J.; Kučerová, D.; Geryk, J.; Krchlíková, V.; Lejčková, B.; Hejnar, J. Precise CRISPR/Cas9 editing of the NHE1 gene renders chickens resistant to the J subgroup of avian leukosis virus. Proc. Natl. Acad. Sci. USA 2020, 117, 2108-2112.

(C) 2020 by the authors. Licensee MDPI, Basel, Switzerland. This article is an open access article distributed under the terms and conditions of the Creative Commons Attribution (CC BY) license (http://creativecommons.org/licenses/by/4.0/). 